\title{
Self-efficacy for taking Preventive Measures against COVID-19 among Undergraduate University Students in Saudi Arabia
}

\author{
Awad Mohammed Al-Qahtani ${ }^{1 *}$ (D), Heba A. Ibrahim ${ }^{2,3}$, Wafaa T. Elgzar ${ }^{2,4}$, Nahid K. \\ Elfeki ${ }^{5}$, Mohammed Ashique K. Shaikh ${ }^{6}$, Ibrahim Ahmed Shaikh7 ${ }^{7}$, Salihah Y. Al \\ Mani ${ }^{8}$, Marwah A. Alessa ${ }^{8}$, Borouj H. Alyami ${ }^{8}$, Alanood M. Alwadei ${ }^{8}$ and \\ Rawan M. Almuqati ${ }^{8}$ \\ ${ }^{1}$ Department of Family and Community Medicine, College of Medicine, Najran University, Najran, Saudi Arabia. \\ ${ }^{2}$ Department of Maternity and Childhood Nursing, College of Nursing, Najran University, Najran, Saudi Arabia. \\ ${ }^{3}$ Department of Obstetrics and Women's Health Nursing, Benha University, Benha, Egypt. \\ ${ }^{4}$ Department of Obstetrics and Gynecologic Nursing, Damanhour University, Damanhour, Egypt. \\ ${ }^{5}$ Department of Community and Mental Health Nursing, College of Nursing, Najran University, Najran, Saudi \\ Arabia. \\ ${ }^{6}$ Pharmacy Services Division, Najran University Hospital, Najran, Saudi Arabia. \\ ${ }^{7}$ Department of Pharmacology, College of Pharmacy, Najran University, Najran, Saudi Arabia. \\ ${ }^{8}$ Internship Student, College of Medicine, Najran University, Najran, Saudi Arabia.
}

*Correspondence: awadresearch17@gmail.com; +966 530540450

(Received: December 20, 2020; accepted: January 14, 2021)

Citation: Al-Qahtani AM, Ibrahim HA, Elgzar WT, et al. Self-efficacy for taking Preventive Measures against COVID-19 among Undergraduate University Students in Saudi Arabia. J Pure Appl Microbiol. 2021;15(1):130-137. doi:10.22207/JPAM.15.1.08

(C) The Author(s) 2021. Open Access. This article is distributed under the terms of the Creative Commons Attribution 4.0 International License which permits unrestricted use, sharing, distribution, and reproduction in any medium, provided you give appropriate credit to the original author(s) and the source, provide a link to the Creative Commons license, and indicate if changes were made. 


\begin{abstract}
The COVID-19 pandemic has imposed various stresses on individuals and communities. Coping with sudden, tense, demanding situations during an infectious disease outbreak requires self-efficacy. Increasing the public's self-efficacy for preventive and control measures is important in the management of the COVID-19 pandemic. This research was aimed at evaluating the self-efficacy and associated factors of students at a public university in the southwest region of Saudi Arabia during the COVID-19 pandemic. This was a cross-sectional study, and a snowball sampling method was used to recruit participants. Data were collected from the beginning of April to the end of June 2020 using an online questionnaire. A total of 761 students were included in the study. The participants' demographic data were collected, and self-efficacy was analyzed using the General Self-efficacy Scale. The results showed that self-efficacy for dealing with the COVID-19 pandemic was moderate in almost half of the students but was low in approximately $25 \%$ of the participants. There were statistically significant associations between self-efficacy regarding the COVID-19 pandemic and gender, college type, marital status, and family income $(p<0.05)$. However, the participants' self-efficacy was not associated with age, residence, or history of chronic illness. In dealing with the COVID-19 pandemic, most students had either moderate or low self-efficacy. Certain demographic variables were positively associated with self-efficacy as perceived by the students. These findings provide data central to the development of self-efficacy initiatives. They may also be useful for the effective implementation of public health preventive behavior programs during the COVID-19 pandemic.
\end{abstract}

Keywords: COVID-19, University students, Self-efficacy, Saudi Arabia

\section{INTRODUCTION}

Coronavirus disease (COVID-19) has led to a global pandemic that started in Wuhan city, China and has affected over 65.8 million people and led to more than 1.5 million deaths worldwide. The disease has presented an unprecedented challenge to public health systems and caused widespread economic and social disruptions. Successful management of this global health crisis requires worldwide collaboration and public responsibility ${ }^{1,2}$. From the beginning of the COVID-19 pandemic, Saudi Arabia took numerous active measures to control the spread of the disease. These measures included travel restrictions, switching students to online learning, quarantines, stopping pilgrimages, suspension of new visa services, and a 24-hour curfew. Despite these measures, the number of positive cases kept increasing, especially after the curfew was partially lifted. Currently, the cumulative number of COVID-19 cases in Saudi Arabia was 361,178 3 .

According to World Health Organization (WHO), management of COVID-19 depends mainly on preventive and protective measures. Strict infection control measures should be applied during isolation, triage, emergencies, and any suspected patient contact ${ }^{5}$. Application of infection control measures requires adequate knowledge and experience. It also requires high self-efficacy (SE) and low perceived barriers ${ }^{6}$. An increase in SE decreases the barriers to improved preventive practices.

Self-efficacy (SE), which is defined as "a person's judgment of their capability to complete a specific behavior or task," is an important aspect of infection prevention measures. The higher the SE of an individual, the greater their compliance with infection control measures and social distancing during pandemics ${ }^{7}$. A recent Saudi study on health providers' knowledge and perception of MERS-CoV reported a significant relationship between SE and intention to implement infection prevention measures ${ }^{8}$. Another study reported that more educated individuals had higher awareness of infectious disease management, which increased their SE for infection control and social distancing'. Moreover, people with higher SE can better manage their emotions and regulate stress. Another study provided evidence of the importance of SE during the COVID 19 pandemic by investigating the impact of psychosocial support for medical staff regarding their sleep during the pandemic ${ }^{10}$. The study found that SE is a vital component of mental health in a time of crisis, 
and it can be enhanced through adequate social support during quarantine. An increase in SE improves understanding, reassurance, courage, and control. It also leads to greater self-confidence in pandemic control and a more optimistic view of the situation ${ }^{11}$. Moreover, $\mathrm{SE}$ is associated with a positive mental state that may improve sleep quality. Individuals with high SE present reasonably steady emotions during stressful situations. They also might experience fewer nightmares and sleep-related worries and less insomnia ${ }^{12}$. High SE also increases concentration and self-control. This evidence supports the significant impact of SE during COVID-19 management in both hospitals and quarantine centers. One study has suggested that SE helps all community members to overcome the barriers and threats to COVID-19 prevention ${ }^{10}$. The current study aimed to evaluate SE and associated demographic variables during the COVID-19 pandemic among Najran University students.

\section{METHODS Study design}

This was a cross-sectional study of students at Najran University, Najran City. Snowball sampling was used to recruit the study participants. The study was conducted from the beginning of April to the end of June, 2020. A web-based questionnaire was used for the study. The questionnaire was distributed via e-mail and social media applications, such as WhatsApp, Facebook, and Twitter, using an online link. Data confidentiality was guaranteed.

\section{Inclusion criteria}

Saudi students with valid e-mail IDs who were active social media users and agreed to participate in the study were included.

\section{Sample size}

The Epi Info 7 program was used to calculate sample size; the sample size for frequency in a population size was 16809 , corresponding to a $99 \%$ confidence level, the anticipated frequency was $50 \%$, and the design effect was $1 \%$. The calculated sample size was 761 students.

Study tools: Two tools were used for data collection.

Tool I was a self-administered questionnaire developed by the researchers after consulting related literature. It was designed to collect demographic information, including gender, age, college type, residence location, marital status, family income, and medical history.

Tool II was the General Self-Efficacy Scale (GSE). It was composed of 10 items ranked on a 4-point Likert scale, from not at all true (1 point) to exactly true (4 points). The overall score was calculated by summing the responses to all 10 items to generate a score of $10-40$, with a greater score representing greater $\mathrm{SE}^{13}$.

\section{Instrument validity and reliability}

After the instrument was developed, it was tested for face, content, and construct validity by a jury of five experts from the fields of nursing and medicine. Instrument reliability was tested using Cronbach's alpha coefficient test $(r=0.875)$.

A pilot study was conducted that included $10 \%$ of the participants. The pilot study aimed to ascertain the clarity and validity of the instruments. The data obtained from the pilot study were not included in the results.

\section{Data collection and analysis}

Data were collected through a webbased questionnaire and were analysed using SPSS version 23 software. Categorical variables are reported as frequency $(\mathrm{n})$ and percentage (\%), and continuous variables are expressed as mean \pm standard deviation (SD). Associations between demographic variables and SE were investigated using Fisher's exact test. $P$ values less than 0.05 were considered statistically significant.

\section{Ethical statement}

The study was reviewed and approved by the Deanship of Scientific Research and the Institutional Review Board of the College of Medicine of Najran University. Formal approval was also obtained from the administration of each college. Students' participation was entirely voluntary and they were informed that they were free to withdraw from the study at any point. Informed consent was obtained from each participant. All data obtained were kept confidential and used for research purposes only.

\section{RESULTS}

Demographic profiles of study participants

The demographics of the study participants are presented in Table 1 . The mean age of the students was $20.27 \pm 4.39$ years; $67.5 \%$ of the participants were female, and $75.5 \%$ resided 
Table 1. Participants' demographic variables $(n=761)$

\begin{tabular}{lll}
\hline Demographic variable & $\mathrm{n}$ & $\%$ \\
\hline Residence & & \\
$-\quad$ Urban & 574 & 75.5 \\
$-\quad$ Semi-urban & 120 & 15.8 \\
$-\quad$ Rural & 66 & 8.7 \\
Gender & & \\
$-\quad$ Male & 247 & 32.5 \\
$-\quad$ Female & 514 & 67.5 \\
College & & \\
$-\quad$ Health sciences & 301 & 39.6 \\
$-\quad$ Non-health sciences & 460 & 60.4 \\
Marital status & & \\
$-\quad$ Married & 116 & 15.2 \\
$-\quad$ Single & 645 & 84.8 \\
Monthly family income & & \\
$-\quad<5000$ SAR & 585 & 76.9 \\
$-\quad$ 5000-10000 SAR & 111 & 14.6 \\
$-\quad>10000 S A R$ & 65 & 8.5 \\
History of chronic illness & & \\
$-\quad$ Yes & 83 & 10.9 \\
$-\quad$ No & 678 & 89.1 \\
Age in years (mean \pm SD) & $20.27 \pm 4.39$ & \\
\hline$\quad \quad$ & \\
\hline
\end{tabular}

in urban areas. More than half $(60.4 \%)$ of the participants were non-health sciences college students, and $84.8 \%$ were single. Slightly more than three-quarters (76.9\%) of the participants had family monthly income of less than 5000 SAR. Only $10.9 \%$ of the participants had a history of chronic disease.

Table 2 provides details of the students' SE during the period of COVID-19 pandemic. It shows that $44.9 \%$ of the participants responded hardly true to the statement I can always solve the difficult problems facing me related to COVID-19. Moreover, $35.7 \%$ of them answered hardly true when asked if they could solve most of the problems caused by social distancing, and one-third (33.5\%) of the participants exactly true when asked if It was easy for them to adhere to the COVID-19 preventive measures.

Fig. 1 shows that $45.9 \%$ of the students had moderate SE for dealing with the COVID-19 pandemic, while more than one-fifth (22.9\%) of them had low SE for dealing with the pandemic.

Table 2. Students' SE during the period of COVID-19 pandemic $(n=761)$

\begin{tabular}{|c|c|c|c|c|c|c|c|c|}
\hline & $n$ & $\%$ & $\mathrm{n}$ & $\%$ & $\mathrm{n}$ & $\%$ & $n$ & $\%$ \\
\hline $\begin{array}{l}\text { I can always solve the difficult problems } \\
\text { related to COVID-19 faced by me. }\end{array}$ & 81 & 10.6 & 342 & 44.9 & 155 & 20.4 & 183 & 24.0 \\
\hline $\begin{array}{l}\text { I am confident in my ability to achieve my } \\
\text { educational goals during COVID-19 outbreak. }\end{array}$ & 110 & 14.5 & 233 & 30.6 & 220 & 28.9 & 198 & 26.0 \\
\hline $\begin{array}{l}\text { It is easy for me to adhere to the COVID- } 19 \\
\text { preventive measures. }\end{array}$ & 73 & 9.6 & 197 & 25.9 & 236 & 31.0 & 255 & 33.5 \\
\hline $\begin{array}{l}\text { I am sure I can handle efficiently the } \\
\text { unexpected events of COVID-19. }\end{array}$ & 87 & 11.4 & 254 & 33.4 & 203 & 26.7 & 217 & 28.5 \\
\hline $\begin{array}{l}\text { I can manage the emergency situations that } \\
\text { arise from the COVID- } 19 \text {. }\end{array}$ & 56 & 7.4 & 206 & 27.1 & 287 & 37.7 & 212 & 27.9 \\
\hline $\begin{array}{l}\text { I can solve most of the problems caused by } \\
\text { social distancing if I make the necessary efforts } \\
\text { to overcome them. }\end{array}$ & 53 & 7.0 & 184 & 24.2 & 275 & 36.1 & 249 & 32.7 \\
\hline My abilities help me cope with home quarantine. & 69 & 9.1 & 217 & 28.5 & 259 & 34.0 & 216 & 28.4 \\
\hline $\begin{array}{l}\text { When I encounter problems related to home } \\
\text { quarantine requirements, I am able to find many } \\
\text { alternative solutions. }\end{array}$ & 69 & 9.1 & 272 & 35.7 & 248 & 32.6 & 172 & 22.6 \\
\hline $\begin{array}{l}\text { Usually, when there are crises arising from } \\
\text { COVID- } 19, \text { I can think of suitable and alternative } \\
\text { solutions. }\end{array}$ & 130 & 17.1 & 218 & 28.6 & 230 & 30.2 & 183 & 24.0 \\
\hline $\begin{array}{l}\text { Usually, I can overcome problems related to } \\
\text { distance education during the spread of the } \\
\text { COVID-19. }\end{array}$ & 81 & 10.6 & 249 & 32.7 & 249 & 32.7 & 182 & 23.9 \\
\hline
\end{tabular}


Table 3 shows statistically significant association $(p<0.05)$ between the participants' SE for the COVID-19 pandemic and gender, college type, marital status, and family income. On the other hand, there was no relationship between the participants' SE and age, residence location, and history of chronic illness.

\section{DISCUSSION}

The COVID-19 epidemic is a global health crisis that has greatly impacted communities and individuals worldwide, destabilized the world economy, and hit the most vulnerable the hardest. It has negatively affected physical, social, and mental health. Many people have suffered the loss of loved ones, leading to severe anxiety and despair.

Self-efficacy (SE) is the cornerstone of most of public health education programs. Effective management of the COVID-19 pandemic requires consistent lifestyle modifications, social distancing, and specific hygienic behaviors. Thus, if SE is increased, pandemic control will be more successful. This is the first study conducted in Saudi Arabia aimed at evaluating the SE of Najran University students during the COVID-19 pandemic, as well its association with demographics. It was aimed at providing important information regarding SE, which will be useful in designing health education programs for Saudi University students.

Self-efficacy is a useful measure of confidence in one's ability to take action and successfully implement preventive health

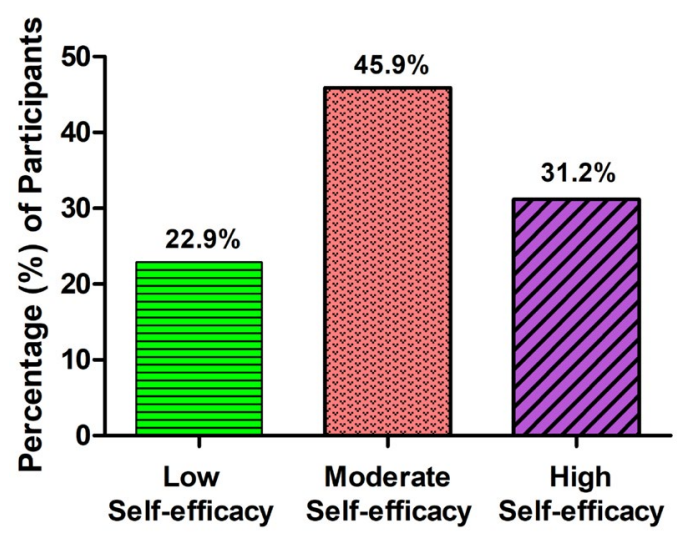

Fig. 1. Total SE scores of Najran University students during the period of COVID-19 pandemic $(n=761)$ behaviors ${ }^{14}$. The results of the present study show that nearly half of the students had moderate SE for dealing with the COVID-19 outbreak. However, less than one-third of the participants had high SE for dealing with the pandemic. Slightly more than one-fifth of the students had low SE for managing the pandemic. These results agree with the findings of Nasir et al. (2020) ${ }^{15}$ who examined the perception of COVID-19 among a Sudanese population and reported that onethird of the participants had low SE for following preventive measures, such as hand hygiene and social distancing. In a cross-sectional study on the relationship between SE and demographic characteristics among Iranian medical students, Seyedi-Andi et al. (2019) ${ }^{16}$ reported moderate SE in a considerable proportion of the participants, and low SE in $25 \%$ of participants. De Zwart et al. $(2009)^{17}$ conducted an international survey on perceived threat, severity, and SE for SARS and other infectious diseases in Asian and European countries. They found that SE was low among participants for SARS and the common cold in all countries included in the study, while SE during SARS was higher in Asian countries than in European countries.

Self-efficacy has been severely affected during the COVID-19 pandemic ${ }^{18}$. In a study aimed to enhance science engagement by raising SE in students during school disruption due to the COVID-19 pandemic, they designed a game that decreased anxiety and increased SE to enhance scientific engagement. The results of the study also suggested that improvement of SE should be the cornerstone of any strategy aimed at improving online learning during the COVID-19 pandemic. Elgzar et al. $(2020)^{19}$ investigated the effect of health belief model-based education on nursing students' health beliefs and knowledge about COVID-19. Before the intervention, both the intervention and control groups had moderate SE. After health belief model-based education, the SE of the intervention group improved significantly. Self-efficacy (SE) may also play an essential role in motivating people to adhere to preventive and protective practices. This idea is supported by a study by Bashirian et al. $(2020)^{20}$ who applied the protection motivation theory to examine the use of protective equipment by medical staff when caring for COVID-19 patients. They reported 
Table 3. Relationship between students' total SE for COVID-19 pandemic and their demographic variables $(n=761)$

\begin{tabular}{|c|c|c|c|c|c|c|c|c|c|}
\hline \multirow[t]{3}{*}{ Socio-demographic data } & \multicolumn{2}{|c|}{ Low SE } & \multicolumn{2}{|c|}{ Moderate SE } & \multicolumn{2}{|c|}{ High SE } & \multirow{3}{*}{$\begin{array}{c}\text { Total } \\
\mathrm{n}\end{array}$} & \multirow[t]{3}{*}{ FET } & \multirow[t]{3}{*}{$P$} \\
\hline & $n$ & $\%$ & $\mathrm{n}$ & $\%$ & $\mathrm{n}$ & $\%$ & & & \\
\hline & \multicolumn{2}{|c|}{$(174)$} & \multicolumn{2}{|c|}{ (349) } & \multicolumn{2}{|c|}{$(238)$} & & & \\
\hline Age & & & & & & & & 7.605 & 0.107 \\
\hline$>20$ & 17 & 25.8 & 37 & 56.0 & 12 & 18.2 & 66 & & \\
\hline $20->25$ & & 133 & 23.4 & 254 & 44.6 & 182 & 32.0 & 569 & \\
\hline$\leq 25$ & 24 & 19.0 & 58 & 46.1 & 44 & 34.9 & 126 & & \\
\hline Residence location & & & & & & & & 2.570 & 0.634 \\
\hline - Urban & 132 & 23.0 & 265 & 46.2 & 177 & 30.8 & 574 & & \\
\hline Semi-urban & 28 & 23.3 & 58 & 48.3 & 34 & 28.4 & 120 & & \\
\hline - $\quad$ Rural & 14 & 21.2 & 26 & 39.4 & 26 & 39.4 & 66 & & \\
\hline Gender & & & & & & & & 17.798 & $0.000^{*}$ \\
\hline Male & 72 & 29.1 & 121 & 49.0 & 54 & 21.9 & 247 & & \\
\hline Female & 102 & 19.8 & 228 & 44.4 & 184 & 35.8 & 514 & & \\
\hline College & & & & & & & & 20.944 & $0.000^{*}$ \\
\hline - $\quad$ Health sciences & 64 & 21.3 & 167 & 55.5 & 70 & 23.3 & 301 & & \\
\hline Non-health sciences & 110 & 23.9 & 182 & 39.6 & 168 & 36.5 & 460 & & \\
\hline Marital status & & & & & & & & 11.769 & $0.002^{*}$ \\
\hline - $\quad$ Married & 13 & 11.2 & 63 & 54.3 & 40 & 34.5 & 116 & & \\
\hline Unmarried & 161 & 25.0 & 286 & 44.3 & 198 & 30.7 & 645 & & \\
\hline Family monthly income & & & & & & & & 10.938 & $0.021^{*}$ \\
\hline$<5000$ SAR & 147 & 25.1 & 264 & 45.1 & 174 & 29.7 & 585 & & \\
\hline 5000-10000 SAR & 21 & 18.9 & 51 & 45.9 & 39 & 35.1 & 111 & & \\
\hline >10000SAR & 6 & 9.2 & 34 & 52.3 & 25 & 38.5 & 65 & & \\
\hline History of chronic illness & & & & & & & & 3.145 & 0.201 \\
\hline - $\quad$ Yes & 21 & 25.3 & 43 & 51.8 & 19 & 22.9 & 83 & & \\
\hline No & 153 & 22.6 & 306 & 45.1 & 219 & 32.3 & 678 & & \\
\hline
\end{tabular}

$\mathrm{aP}<0.05$, Fisher Exact test (FET).

that SE was significantly correlated with other protection motivation theory constructs and recommended that special emphasis be placed on SE and knowledge relating to COVID-19 when discussing adherence to self-protective measures. Spoorthy et al. (2020) $)^{21}$ conducted a systemic review of the mental health problems encountered by healthcare workers and patients during the COVID-19 pandemic. They found that poor SE was one of the psychological factors associated with stress, anxiety, insomnia, and depressive symptoms, and the results suggested that SE could be enhanced by family and social support.

The present study investigated the associations between students' SE during the COVID-19 outbreak and their socio-demographic characteristics. The results showed statistically significant associations between the students' SE and gender, college type, marital status, and family income. These findings differ from the findings of
Yildirim and Guler (2020) ${ }^{22}$ who studied COVID19-related SE and knowledge in 3,190 Turkish participants using an online questionnaire. The SE during COVID-19 was uniquely predicted by mental health as well as gender, chronic disease, and age. They recommended the development of SE-based educational interventions aimed at improving the public mental health during an epidemic. In our study, there was no significant relationship between the students' SE and their age or history of chronic disease. The difference between the two studies regarding the association of age with SE may be attributed to the different age groups of the participants in the studies; Yildirim and Guler $(2020)^{22}$ studied SE among an adult population, whereas the mean age in the current study was 20.27 years. In another study, Li et al. $(2020)^{23}$ investigated the relationship between COVID-19 protective behaviors in the USA and social media use, risk perception, and demographic 
characteristics. Their findings revealed that sociodemographic attributes, including gender, race, and marital status were major factors associated with adherence to protective behaviors and testing for COVID-19. Moreover, Seyedi-Andi et al. $(2019){ }^{16}$ reported significant associations between students' SE and demographic variables such as college type, monthly family income, and gender. Participants with higher family income, females, and students attending medical or dental college had higher SE scores. There was no significant association between SE score and marital status. Multiple linear regression analysis revealed a remarkably high positive and direct relationship between SE and family income.

Most of the studies mentioned here emphasized the importance of SE in infectious disease control. Therefore, public awareness efforts should be directed toward raising public SE. In addition, the factors that influence SE should be thoroughly investigated.

\section{CONCLUSION}

Based on the study results, we concluded that approximately one-half of Najran University students had moderate $\mathrm{SE}$, and more than onefifth of them had low SE for dealing with the COVID-19 pandemic. There were statistically significant associations between the participants' SE during the COVID-19 pandemic and gender, college, marital status, and family income.

Implications of the study

Self-efficacy (SE) is particularly important for adherence to self-protection behaviors and precautions and overcoming psychological stress. A population with a high SE promotes the practice of proper social distancing and healthy behaviors without supervision from the authorities. It also helps to increase an individual's internal capacity to protect their families and communities from COVID-19 infection. The data obtained in this study provide valuable information for policy makers regarding the SE of students at Najran University, Saudi Arabia during the COVID-19 pandemic. The dissemination of such data is essential for the development of evidence-based interventions. Decision makers may use these data to produce social interventions that increase public SE. It will also enrich the COVID-19 international database on the role of SE during pandemics.

\section{ACKNOWLEDGMENTS}

The authors are grateful to the students who voluntarily took part in this study.

\section{CONFLICT OF INTEREST}

The authors declare that there is no conflict of interest.

\section{AUTHORS' CONTRIBUTION}

All authors listed have made a substantial, direct and intellectual contribution to the work, and approved it for publication.

\section{FUNDING}

None

\section{DATA AVAILABILITY}

All datasets generated or analyzed during this study are included in the manuscript and/or the Supplementary Files.

\section{ETHICS STATEMENT}

Ethics statement applicable and included in the methodology section.

\section{REFERENCES}

1. World Health Organization a. Weekly epidemiological update-8 December 2020. Available at: https:// www.who.int/publications/m/item/weeklyepidemiological-update-8-december-2020 (Accessed on $12 / 12 / 2020)$.

2. World Health Organization b. Impact of COVID-19 on people's livelihoods, their health and our food systems. Available at: https://www.who.int/news/item/1310-2020-impact-of-covid-19-on-people's-livelihoodstheir-health-and-our-food-systems (Accessed on 12/12/2020).

3. Ministry of Health, Saudi Arabia. 2020. $\mathrm{MOH}$ publications. Available at: https://www.moh.gov. sa/en/Ministry/MediaCenter/Publications/Pages/ covid19.aspx. Accessed on: 21/12/2020.

4. Saudi Center for Disease Prevention and Control. 2020. (COVID-19) Disease Interactive Dashboard. Available at: https://covid19.cdc.gov.sa/daily-updates/. Accessed on: 12/12/2020.

5. World Health Organization. Clinical management of severe acute respiratory infection (SARI) when COVID-19 disease is suspected. Available at: https://www.who.int/publications/i/item/clinicalmanagement-of-covid-19. Accessed on: 12/12/2020. doi: 10.15557/PiMR.2020.0003

6. Hui DS, Azhar El, Madani TA, et al. The continuing 2019nCoV epidemic threat of novel coronaviruses to global health - the latest 2019 novel corona virus outbreak in Wuhan, China. Int J Infect Dis. 2020;91:264-266. doi: 10.1016/j.ijid.2020.01.009. 
7. Bandura A. Self-efficacy: Toward a unifying theory of behavioral change. Psychol Rev. 1977;84(2):191-215. doi:10.1037//0033-295x.84.2.191

8. Alshammari F. Knowledge and Perception of Health Practitioners towards MERS-CoV in Hail Region, Kingdom of Saudi Arabia. Am J of Nurs Res. 2018;6(1):12-17. doi: 10.12691/ajnr-6-1-2

9. Al-Mohrej A, Agha S. Are Saudi medical students aware of middle east respiratory syndrome coronavirus during an outbreak? J Infect Public Health. 2017;10(4):388395. doi:10.1016/j.jiph.2016.06.013.

10. Xiao $H$, Zhang $Y$, Kong D, Li S, Yang N. The Effects of Social Support on Sleep Quality of Medical Staff Treating Patients with Coronavirus Disease 2019 (COVID-19) in January and February 2020 in China. Med Sci Monit. 2020;5(26):e923549. doi: 10.12659/ MSM.923549

11. Segrin C, Passalacqua SA. Functions of loneliness, social support, health behaviors, and stress in association with poor health. Health Commun. 2010;25(4):312 322. doi:10.1080/10410231003773334

12. Bihlmaier I, Schlarb AA: Self-efficacy and sleep problems. Somnologie. 2016;20:275-280. doi: 10.1007/s11818-016-0085-1

13. Schwarzer R, Jerusalem M. Generalized Self-Efficacy scale. In: Johnston M, Wright S, Weinman J. Measures in Health Psychology: A User's Portfolio. Windsor: NFER-NELSON; 1995:35-37.

14. Champion VL, Skinner CS. The Health Belief Model. In Health Behavior and Health Education: Theories, Research, and Practice. K. Glanz, Rimer, B.K., Viswanath, K. (Eds.) San Francisco, CA: Jossey Bass; 2008:45-62.

15. Nasir EF, Yagoub HMA, Alhag AK. Study of the Sudanese perceptions of COVID-19: Applying the Health Belief Model. medRxiv. 2020. doi: 10.1101/2020.05.28.20115477

16. Seyedi-Andi SJ, Bakouei F, Adib Rad H, Khafri S, Salavati A. The relationship between self-efficacy and some demographic and socioeconomic variables among
Iranian Medical Sciences students. Adv Med Educ Pract. 2019;10:645-651. doi: 10.2147/AMEP.S185780

17. de Zwart O, Veldhuijzen IK, Elam G, et al. Perceived Threat, Risk Perception, and Efficacy Beliefs Related to SARS and Other (Emerging) Infectious Diseases: Results of an International Survey. Int I Behav Med. 2009;16(1):30-40. doi:10.1007/s12529-008-9008-2

18. Yang $\mathrm{X}$, Zhang $\mathrm{M}$, Kong $\mathrm{L}$, Wang $\mathrm{Q}$, Hong J. The Effects of Scientific Self-efficacy and Cognitive Anxiety on Science Engagement with the "Question-ObservationDoing-Explanation" Model during School Disruption in COVID-19 Pandemic. J Sci Educ Technol. 2020. doi: 10.1007/s10956-020-09877-x

19. Elgzar WT, Al-Qahtani AM, Elfeki NK, Ibrahim HA. COVID-19 Outbreak: Effect of an Educational Intervention Based on Health Belief Model on Nursing Students' Awareness and Health Beliefs at Najran University, Kingdom of Saudi Arabia. Afr J Reprod Health. 2020;24(2):78-86.

20. Bashirian S, Jenabi E, Khazaei S, et al. Factors associated with preventive behaviours of COVID-19 among hospital staff in Iran in 2020: an application of the Protection Motivation Theory. $J$ Hosp Infect. 2020;105(3):430-433. doi: 10.1016/j.jhin.2020.04.035

21. Spoorthy MS, Pratapa SK, Mahant S. Mental health problems faced by healthcare workers due to the COVID-19 pandemic-A review. Asian J Psychiatr. 2020;51: 102119. doi: 10.1016/j.ajp.2020.102119

22. Yildirim M, Guler A. COVID-19 severity, self-efficacy, knowledge, preventive behaviors, and mental health in Turkey [Published online ahead of print, $2020 \mathrm{Jul}$ 16]. Death Stud. 2020. doi:10.1080/07481187.2020. 1793434

23. Li S, Feng B, Liao W, Pan W. Internet Use, Risk Awareness, and Demographic Characteristics Associated With Engagement in Preventive Behaviors and Testing: Cross-Sectional Survey on COVID-19 in the United States. J Med Internet Res. 2020;22(6):e19782. doi: 10.2196/19782 